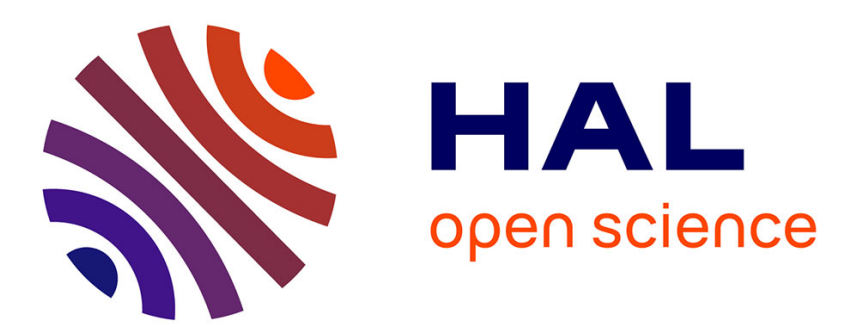

\title{
Prediction of the Biomechanical Effects of Compression Therapy on Deep Veins Using Finite Element Modelling
}

Pierre-Yves Rohan, Pierre Badel, Bertrand Lun, Didier Rastel, Stéphane Avril

\section{To cite this version:}

Pierre-Yves Rohan, Pierre Badel, Bertrand Lun, Didier Rastel, Stéphane Avril. Prediction of the Biomechanical Effects of Compression Therapy on Deep Veins Using Finite Element Modelling. Annals of Biomedical Engineering, 2015, 43 (2), pp.314-324. 10.1007/s10439-014-1121-6 . hal-01137356

\section{HAL Id: hal-01137356 https://hal.science/hal-01137356}

Submitted on 30 Mar 2015

HAL is a multi-disciplinary open access archive for the deposit and dissemination of scientific research documents, whether they are published or not. The documents may come from teaching and research institutions in France or abroad, or from public or private research centers.
L'archive ouverte pluridisciplinaire HAL, est destinée au dépôt et à la diffusion de documents scientifiques de niveau recherche, publiés ou non, émanant des établissements d'enseignement et de recherche français ou étrangers, des laboratoires publics ou privés. 


\section{Prediction of the biomechanical effects of compression therapy on deep veins using Finite Element modelling}

Pierre-Yves Rohan ${ }^{1}$, Pierre Badel ${ }^{1}$, Bertrand Lun ${ }^{2}$, Didier Rastel $^{3}$, Stéphane Avril ${ }^{1}$

${ }^{1}$ Ecole Nationale Supérieure des Mines de Saint-Etienne, CIS-EMSE, CNRS:UMR5146, LCG, F-42023 Saint Etienne, France

${ }^{2}$ SIGVARIS Applied Research Department, Saint-Just-Saint-Rambert, France

${ }^{3}$ Vascular physician, Grenoble, France

Abbreviated title for the running head: Biomechanical effects of compression therapy on deep veins

Address for correspondence:

Stéphane AVRIL

Center for Biomedical and Healthcare Engineering

Ecole Nationale Supérieure des Mines de Saint Etienne

158 cours Fauriel, 42023 Saint-Etienne Cedex 2

France

Phone : +33(0)477420188,

Fax : +33(0)477499755

Email : avril@emse.fr 


\section{Abstract and key terms}

Clinicians generally assume that Medical Compression Stockings (MCS) work by reducing vein luminal diameter and, in this way, help to prevent blood pooling. Conflicting results have been reported however in the case of lower leg deep veins which call into question this hypothesis. The purpose of this contribution is to study the biomechanical response of the main lower leg deep veins to elastic compression and muscle contraction with the objective of improving our current understanding of the mechanism by which MCS convey their benefits. The development of a finite-element model of a slice of the lower leg from MR images is detailed. Analysis of the finite-element model shows that the contribution of the MCS to the deep vein diameter reduction is rather small, and in fact negligible, compared to that of the contracting muscle (3\% and $9 \%$ decrease in the vein cross-sectional area with a grade II compression stocking in the supine and standing positions respectively, while complete collapse was obtained at the end of muscle activation). A more accurate representation of the muscle activation is eventually proposed to study the effect of muscle contraction on a vein wall. The impact on the venous blood draining is discussed.

Key terms: Calf, Medical Compression Stockings, venous, soft tissues

\section{Introduction}

Medical Compression Stockings (MCS) are considered as a mainstay in the treatment options for patients suffering from lower leg deep venous insufficiency ${ }^{11}$. They have been shown to be very effective in (i) preventing and managing Deep Venous Thrombosis (DVT) ${ }^{6}$, post-thrombotic syndrome ${ }^{33}$ and ulcers of the leg ${ }^{8}$, (ii) improving abnormal venous return ${ }^{19}$ and (iii) improving muscle calf pumping function ${ }^{24}$. Like other forms of mechanical treatments, MCS are generally 
thought to act by reducing vein luminal diameter ${ }^{9}$ and, thereby, preventing blood pooling or stasis ${ }^{2}$. In a clinical study by Partsch et al. ${ }^{29}$ for example, on a population composed of 9 healthy subjects and 5 patients suffering from superficial venous insufficiency, the authors showed that an external compression of $30-40 \mathrm{mmHg}$ lead to a decrease in the posterior tibial deep vein crosssection.

Conflicting results however have been reported in the literature. Mayberry et al. ${ }^{23}$ for example, studied the effect of 30-40 $\mathrm{mmHg}$ and 40-50 mmHg elastic compression on 10 healthy patients and 16 patients suffering from deep venous insufficiency. Their results showed that elastic compression produced a decrease in superficial vein cross-sectional area but had no effect on the femoral and popliteal deep veins considered in the study. The authors even reported a small - but significant - increase in the popliteal deep vein cross-sectional area which lead them to conclude that MCS only drains the blood from superficial to deep veins in the standing position. These results underline the lack of comprehension regarding the mechanisms by which elastic compression achieve their medical goals on patients suffering from lower leg deep venous insufficiency. More importantly, these results emphasize the need to address the key question of whether or not the benefits of action of MCS are correlated to a decrease in the vein luminal cross-sectional area.

The difficulties related to in situ explorations make the development of simulation tools especially attractive to study the response of deep veins to external compression. Computational models have been developed by ${ }^{1672534}$ to investigate the change in deep vessel cross section and have focused primarily on the treatment of Deep Venous Thrombosis (DVT) using Intermittent Pneumatic Compression (IPC). Amongst the simplifying assumptions however, the authors assumed an ideal geometry for all the deep veins and did not account for the differences between the intra-muscular and inter-compartment deep veins amongst other parameters. 
Another important aspect of compression therapy which has not been addressed in the literature, as far as the authors are concerned, is the influence of muscular contraction on the response of deep veins to external compression. Many clinical studies suggest that MCS contribute to improving the muscle pump in patients with an impaired muscle pump ${ }^{14}$. However, this has never been studied from a biomechanical perspective.

The purpose of this work is to study transmission of pressure in the soft tissues of the lower leg during external compression with and without muscle activation to improve our understanding of the main biomechanical parameters affecting the response of lower leg deep veins to external compression. To this end, we created two finite-element models - one for the study of intramuscular veins and another one for inter-muscular veins - from MR images of the calf cross section that replicate the major features of the lower leg geometry, simulated the biomechanical response of the leg to the combined action of elastic compression and muscular contraction and studied the decrease in vein lumen cross-section. We also performed a parametric study to evaluate the sensitivity of the model to different input parameters. Specifically, we examine the effects of position (standing/lying), the model parameters of the muscles, vein wall and fascia. Finally, we refined the study with a more accurate representation of the muscle to characterize the effect of muscle contraction on a vein wall.

\section{Materials and Methods}

The acquisition and segmentation of the MR images to create a geometric model are described in sections 2.1. and 2.2. General mechanical considerations such as constitutive laws, boundary conditions and contact are detailed in section 2.3. The numerical approaches developed to study the biomechanical response of intra-muscular veins and inter-compartment veins to elastic 
compression and muscular contraction are then presented in sections 2.4. and 2.5. The development of two different models (rather than one) was motivated by the convergence difficulties encountered when all the deep veins were combined into one model. As a verification step, the muscle activation of a simplified 3D model of the leg is simulated using the Finite Element (FE) formulation of the Hill muscle model proposed by ${ }^{5}$ in section 2.6.

\subsection{Magnetic resonance imaging of the calf}

The data was acquired on a volunteer aged 45 following informed consent and according to a protocol which was validated by the local institutional ethics committee. The left calf was imaged in the supine position using a $1.5 \mathrm{~T}$ Avanto Siemens MR system. The imaging protocol was a spin-echo sequence. 15 slices of image data were acquired, showing the calf cross section in 3.9 $\mathrm{mm}$ increment along the length of the calf and pixel resolution of $0.78 \mathrm{~mm} \times 0.78 \mathrm{~mm}$. To avoid compression of the calf due to its weight, the leg was supported at the ankle.

\subsection{Geometrical modelling}

\subsubsection{Segmentation}

The different components of the calf are segmented on the MR image slice using a custom-built MATLAB ${ }^{\circledR}$ subroutine (figure 1). (i) The skin and bones (tibia and fibula) are segmented automatically using thresholding and smoothing using a degree 5 Fourier polynomial to remove noise. (ii) The adipose tissue, the muscular aponeurosis and the four muscle compartments (namely the anterior tibia compartment (ATC), lateral compartment (LC), superficial posterior compartment (SPC) and deep posterior compartment (DPC) respectively) are hand segmented and smoothed using a degree 5 Fourier polynomial. The SPC is divided into the soleus muscle 
and the gastrocnemius muscles (interior and exterior). (iii) The intra-muscular vein model is made up of one of the soleus veins (figure 1(a)). This is, according to clinical studies, the site where thrombi start in the majority of patients ${ }^{27}$ and is, of course, of major interest given the potentially high impact of the results (as DVT is a common surgical complication). The model developed to study inter-compartment veins consists of both the posterior tibial and peroneal veins and arteries (figure 1(b)). The posterior tibial and peroneal arteries are included in our model because of their assumed contribution in and impact on the response of the neighboring veins. For each vessel, segmentation is performed by the user who selects points on the vein inner wall (highest contrast of grey level). The inner contour of the vein is then defined as the best ellipse that fits the data points in the least squares sense. (iv) The MCS is modelled as a circle centred at the centre of gravity of the calf with a circumference equal to manufacturers recommendations (leg circumference in MRI slice was measured as $260 \mathrm{~mm}$ and the corresponding rest MCS circumference as $188 \mathrm{~mm}$ ).

\subsubsection{Reconstruction}

The data points are imported in ABAQUS®ICAE and the geometry of the different constituents reconstructed individually using a custom-built PYTHON® subroutine (figure 1). For each vein, the thickness of the vein wall is taken as $10 \%$ of the vein lumen (average radius of the segmented ellipse) based on the experimental measurements of Martinez et al. ${ }^{21}$. This thickness is added to the ellipse dimensions to define the outer contour of the vein wall. Similarly, the wall thickness to radius ratio of posterior tibial and peroneal arteries was assumed to be $0.1^{13} 22$. For the muscular aponeurosis a thickness of $1 \mathrm{~mm}$ is defined by performing an offset of the segmented contour to 
be consistent with the values reported in the literature regarding the mean thickness of the deep fascia in the lower limb ${ }^{32}$.

\subsection{Geometrical and mechanical considerations}

\subsubsection{Materials}

A summary of the constitutive properties used to describe the mechanical behaviour of the different soft tissues is given in Table I. We assume, for simplicity, that soft tissues are homogeneous, isotropic (for the muscles, this means that we assume that all muscles fibres are normal to the transverse sections where the MR images are acquired) and incompressible (constant volume). Biological soft tissues are represented using a Neo-Hookean hyper-elastic model. Constitutive parameters available in the literature are used (Table 1) except for the vein walls. In that case, the values identified in a recent study by our group ${ }^{31}$ by FE updating are used (one in the supine position and one in the standing position respectively). The MCS is represented using a linear elastic law (Hooke law). The mechanical characterisation of the MCS in the circumferential direction performed in the previous study based on the French norm ${ }^{1}$ are used. Bones are regarded as infinitely rigid as compared to the surrounding soft tissues.

\subsubsection{Internal blood pressure and pre-stress in the vein wall}

The intravascular pressure is accounted for by a constant pressure applied on the inner surface of the vein wall. For the veins, the pressure imposed is $15 \mathrm{mmHg}$ in the supine position and $90 \mathrm{mmHg}$ in the standing position. For the arteries, the internal pressure imposed is $100 \mathrm{mmHg}$ and $195 \mathrm{mmHg}$ respectively in the supine and the standing positions. This pressure load is responsible for an initial pre-stress of the vessel wall before applying compression, which is 
considered by applying an initial circumferential pre-stress in the wall to counterbalance this pressure. The value of the circumferential pre-stress in each element of the vessel wall is determined by applying the Laplace law.

\subsubsection{Finite element discretization using ABAQUS®}

Plane strain is assumed in this study to perform the two-dimensional analysis. Moreover, soft tissues are considered as nearly incompressible. The different parts of the model are therefore meshed with plane strain hybrid elements (CPE4H and CPE3H in Abaqus $\left.{ }^{\circledR}\right)$ and truss elements (T2D2 in Abaqus®). Local mesh refinement is performed in and around the vein wall. Five elements are imposed in the radial direction (thickness) of the vein and arterial walls following a convergence study based on the reduction of the vein cross-section in response to elastic compression. The final mesh consists of 40000 elements and about 130000 degrees of freedom.

\subsubsection{Boundary conditions}

The tibia and fibula are fixed in this model.

\subsubsection{Contact}

A summary of the contact and constraint parameters used in the model is given in Table II. The contact is enforced using a pure master-slave contact algorithm. To the best knowledge of the authors, no studies have been reported in the literature regarding the in vivo friction between internal soft tissues of the lower leg. A coulomb friction model was therefore used with a friction coefficient of 0.1 , based on the experimental results of ${ }^{3}$ who reported experimental values for the coefficient of friction between the finger flexor tendons and the structures over which they slide. 


\subsubsection{Muscle activation}

The biomechanical action of muscle activation on the main deep vein walls is modelled as pressure boundary conditions imposed on the internal faces of all the boundaries of the muscle. This pressure load increases the hydrostatic pressure in the muscle which, according to ${ }^{15}$, are correlated with intra-muscular pressure. During muscle activation, the pressure load is increased until the deep veins are collapsed. In this work, the muscle activation of the soleus muscle of the SPC and the DPC are considered as illustrated in figure 1.

\subsubsection{Solution technique}

The resolution is performed via an implicit scheme. The default convergence criteria of the Newton-Raphson algorithm in ABAQUS/Standard are used. The numerical strategy to study the response of intra-muscular lower leg deep veins to external compression and muscle activation is summarized in figure 2. The numerical strategy to study the biomechanical response of intercompartment lower leg deep veins consists of one supplementary step designed to account for the interaction between the inter-compartment veins and the muscle compartments. The whole process is summarized in figure 3.

\subsection{Parametric study}

A parametric study was performed to investigate the influence of the following parameters:

- Position (supine / standing)

Internal blood pressure loads and material properties of the vein and artery walls are imposed according to the position as detailed previously.

- Muscular aponeurosis impairment 
Three types of muscular aponeuroses are introduced by scaling the reference parameters $\mathrm{C}_{10}$ and $\mathrm{K}$ of the Neo-Hookean strain energy function by factors $1,1 / 3$ and $1 / 1000$ respectively. These correspond respectively to a healthy (reference) aponeurosis, an impaired aponeurosis, and a completely degenerated aponeurosis in the mechanical sense i.e. the mechanical action is virtually inexistent.

- External compression

Compression stockings are commercially available in four categories of compression levels in France, defined according to an official norm, and prescribed according to the severity of the pathology to be treated. Three MCS were introduced in this study to study the influence of the three strongest compression levels on deep veins i.e grades II $(15-20 \mathrm{mmHg})$, III $(20-30 \mathrm{mmHg})$ and IV (30-40 $\mathrm{mmHg})$.

\section{- Tangent modulus of the vein}

Three types of veins are introduced by scaling the reference tangent modulus $\mathrm{E}$ of the vein identified by ${ }^{31}$ by factors $1 / 3,3$ and 10 respectively in both the supine and standing positions. The corresponding parameters $\mathrm{C}_{10}$ and $\mathrm{K}$ of the Neo-Hookean Strain energy function are inferred. - Type of muscle

Three types of muscles are introduced by scaling separately the reference parameters $\mathrm{C}_{10}$ and $\mathrm{K}$ of the Neo-Hookean Strain energy function by factors $1 / 3,3$ and 10 respectively to evaluate the influence of inter-subject variability on the biomechanical response of deep veins.

\subsection{Refined approach used for modelling muscle activation}

It is assumed in this work that the biomechanical action of muscle activation can be modelled as a pressure load imposed on the internal faces of all the boundaries of the muscle. In the case of the 
intra-muscular vein, this pressure load is constant all around the vein wall. To have more insights on this aspect, muscle activation is modelled using the Finite Element formulation of the Hill muscle model proposed by ${ }^{5}$. This model was implemented using the USERMAT functionality of ANSYS ${ }^{26}$. The muscle activation of a simplified 3D muscle with an intramuscular vein is considered. On order to evaluate the influence of edge-effect, three geometries are designed, illustrated in figure 4, with the vein centered (figure 4(a)), slightly away (offset of $0.5 \mathrm{~cm}$ ) from the center (figure 4(b) and further away (offset of $0.8 \mathrm{~cm}$ ) from the center (figure 4(c)).

\subsection{Post-analysis}

\subsubsection{Biomechanical response of the deep veins to the combined action of elastic compression and muscle activation}

The biomechanical response of deep veins to the combined mechanical action of external compression and muscle activation is presented as the normalized variation of the cross section (final cross sectional area / initial cross sectional area) as a function of the normalized muscle activation (pressure load / maximum pressure load). The ordinate at the origin corresponds to the decrease in cross-sectional area due to external compression only (zero muscle activation).

\subsubsection{Parametric study}

The relative influence of each parameter set listed in section 2.4. (denoted $\mathrm{X}_{\mathrm{i}}$ in this paragraph to make the explanation easier) on the biomechanical response of the deep veins to elastic compression and muscle activation is represented as a function of the relative influence on (a) the variation of the cross section of the vein (denoted $\mathrm{A}_{\mathrm{i}}$ ) and (b) the muscle activation (pressure boundary condition) required to collapse the vein completely (denoted $\mathrm{P}_{\mathrm{i}}$ ). The normalization is 
performed as followed (i) each parameter set $X_{i}$ is scaled to bring all values into the range $[-1,1]$. (ii) The corresponding normalized set of variation of the cross section $A_{i}$ (final cross sectional area / initial cross sectional area) due to elastic compression only is calculated. (ii) The corresponding muscle activation (pressure boundary condition) $\mathrm{P}_{\mathrm{i}}$ required to completely collapse the vein is also computed. (iii) A simple linear regression is then used to calculate the slopes $S 1_{\mathrm{i}}$ and $\mathrm{S}_{\mathrm{i}}$ of the plots $\left(\mathrm{X}_{\mathrm{i}}, \mathrm{A}_{\mathrm{i}}\right)$ and $\left(\mathrm{X}_{\mathrm{i}}, \mathrm{P}_{\mathrm{i}}\right)$ respectively. The normalized slopes are then calculated as the ratio $S 1_{\mathrm{i}} / \max \left(\mathrm{S} 1_{\mathrm{i}}\right)$ and $\mathrm{S} 2_{\mathrm{i}} / \max \left(\mathrm{S} 2_{\mathrm{i}}\right)$ respectively to bring all the values in the range $[0 \%, 100 \%]$.

\section{Results}

\subsection{Transmission of pressure during compression in the supine position}

The distribution of hydrostatic pressure predicted by the model during a grade II external compression $(15-20 \mathrm{mmHg})$ in the supine position is depicted in figure 5. The resulting pressure field is heterogeneous with higher pressures located in the superficial soft tissues.

\subsection{Variation of vessel diameter as a function of the pressure transmitted through the soft tissues and muscle activation}

\subsubsection{Biomechanical response of the intra-muscular vein}

The responses of the intramuscular vein in both the supine and standing positions are depicted in figure 6 . When there no muscle activation (ordinate at the origin), the graph gives the normalized variation of the cross section (final cross sectional area / initial cross sectional area) due to elastic compression only. Figure 6 shows that the decrease of the vein cross-sectional area due to a grade II compression stocking is of the order of $3 \%$ in the standing position and of the order of $9 \%$ in 
the supine position. During muscle activation, the graph gives the normalized variation of the cross section due to the combined action of elastic compression and muscle activation. Our results show that the deep vessel cross section is reduced until complete collapse following a nonlinear response characteristic of collapsible tubes. It can also be observed, from the geometries of the veins accompanying figure 6 that the vein has a larger bending stiffness in the standing position than in the supine position i.e. the vein wall has a higher resistance in the standing position its cross-section is less distorted (ovalises a smaller amount) for the same decrease in transmural pressure.

\subsubsection{Biomechanical response of the inter-muscular veins}

Likewise, the biomechanical response of the inter-compartment veins and arteries in the supine position is given in figure 7. Each component has a distinct response: arteries are less affected than veins and globally, tibial posterior veins are the most affected by both external compression and muscle activation (15-20\% decrease in cross sectional area due to compression and about 90 $\%$ decrease due to muscle activation).

\subsection{Parametric study}

The relative influence of each parameter on (i) the average variation of the cross-sectional vein area and (ii) the muscle activation (pressure load) needed to collapse the deep veins is summarized on the bar chart in figure 8 . Based on the results, it can be summarized that the biomechanical response of veins is subject to three main mechanical factors: the position (supine/standing), the stiffness of the muscles $\left(\mathrm{C}_{10}\right.$ parameter) and the external compression applied on the leg. 


\subsection{Stress profile of muscle activation in transverse plane}

The hydrostatic pressure exerted on the vein contour in response to muscle activation is extracted from the refined activation model presented in subsection 2.7. The results for the three vein positions is illustrated in Figure 9. When the vein is at the center of the muscle (geometry A), the biomechanical action of muscle on the vein contour is constant. Then, the more the vein is moved out of the center, the more the hydrostatic pressure profile changes.

\section{Discussion}

The clinical benefits of wearing MCS are generally attributed to a reduction of the vein luminal diameter and, as a result, to prevention in blood pooling (in the veins). This has never been conclusively demonstrated for lower leg deep veins however. As a matter of fact, conflicting results have been reported which call into question this hypothesis. The purpose of this contribution was therefore to study the biomechanical response of the main lower leg deep veins to elastic compression and muscle contraction with the objective of improving our current understanding of the mechanism by which MCS convey their benefits.

The results obtained in this study confirm those of clinical studies showing that MCS have virtually no effect on reducing the cross-sectional area of deep veins in the standing position (figure 6). In a study including 30 volunteers (17 normal legs, 13 varicose legs), Lord and Hamilton ${ }^{20}$ reported that $20-30 \mathrm{mmHg}$ stockings did not compress deep calf veins (posterior tibial veins, peroneal veins, and soleal veins) when the wearer stood erect. This is in good agreement with the simulation results reported here with a grade II MCS. Similarly, using a Gscan ${ }^{\circledR}$ machine (Esaote, Genova), Partsch et al. ${ }^{30}$ reported that deep veins are slightly narrowed 
by an external pressure of $42 \mathrm{mmHg}$ in the standing position - which is twice the pressure exerted by a grade II MCS - and are only clearly compressed by an external pressure of more than 80 $\mathrm{mmHg}{ }^{30}$. Using ultrasound, Partsch et al. ${ }^{29}$ also reported complete occlusion of deep lower leg veins (Posterior Tibial Vein) in the standing position with about $70 \mathrm{~mm} \mathrm{Hg}$ (maximum 90 $\mathrm{mmHg}$ ) of external pressure. Overall, these results are also coherent with the hypothesis made by Mayberry et al. ${ }^{23}$ that "elastic stockings are not capable of exerting their effects in the upright position" through several centimeters of soft tissues, a rigid fascia layer and in the presence of a significant column of hydrostatic pressure.

Our results also show that, in the standing position, it is mainly muscle contraction that is responsible for narrowing deep veins luminal diameter, the interface pressure applied by commercially available MCS being insufficient to have a significant impact. This mechanism (referred to as the calf muscle pump in the literature), although well established in the clinical literature ${ }^{924}$, had never been modelled before with the Finite Element Method. The proposed numerical approach allows simulating complete vein collapse of lower leg deep veins due to elastic compression and muscle activation. The refined approach used for modelling muscle activation detailed in section 2.7. is also in good agreement with the functional approach used in section 2.3.6. Our results, however, strongly suggest that the functional approach used in ABAQUS is valid only insofar as the geometry is close to the "ideal" situation simulated in section 2.7. Indeed, the more the vein is far from the center of symmetry, the more the pressure profile on the vein wall changes (figure 9).

Nonetheless, the results computed with the proposed numerical approach yield (normalised) pressure-area curves for the soleus vein (figure 6) that are in good agreement with those reported for collapsible tubes ${ }^{17} 18$ and in vivo on human leg veins ${ }^{4}$. The proposed approach 
therefore, seems to give acceptable results from the perspective of the deformation of the soleus vein.

Overall, the simulation results (main trends) are all coherent with MRI observations and clinical results reported in the literature (section 4.1. above). This supports the idea that the assumptions made in this study regarding the biological soft tissues (homogenous, isotropic and their representation with a Neo-Hookean hyper-elastic constitutive model) are acceptable.

Similar biomechanical models reported in the literature ${ }^{72534}$ that have been focused on the treatment of Deep Venous Thrombosis (DVT) using Intermittent Pneumatic Compression (IPC) and which are based on the pioneer work by Kamm and his coworkers ${ }^{16}$. In these studies, (i) personalization of the vein geometry was very basic (in ${ }^{25}$ - which is by far the most complex model ever published - the geometry, diameter and wall thickness of all the deep veins are identical and fixed by the authors because of the relatively poor quality of the MR images), (ii) the question of sliding has never been addressed no more than (iii) the question of the muscle activation.

A special effort has been made in this study to improve the realism of the model by capturing a larger amount of details. This has allowed us to gain better insights into the biomechanical response of lower leg deep veins. In particular, our results suggest that intramuscular veins and inter-compartment veins have different responses to external compression and muscle activation: (i) Intra-muscular veins are embedded in soft tissues, and in that case, we observed that it is primarily the increase in pressure in the surrounding soft tissues that is responsible for narrowing and collapsing the vein. (ii) Inter-compartment veins, on the other hand, are embedded in the loose connective tissue of the fascia constituting the interface between muscle compartments, and in that respect, are sensitive to the deformation of the muscles.

From a clinical point of view, the results reported in this study suggest that MCS actually 
act on the micro-circulation. Indeed, in a previous study by our group ${ }^{31}$, we reported that MCS are effective in reducing the vein luminal diameter of lower leg superficial veins. In this contribution, we report that, in good agreement with clinical studies, MCS have only but a small effect in narrowing lower leg deep veins in the upright position. As a matter of fact, Mayberry et al. ${ }^{23}$ for example observed that that elastic compression produced a decrease in superficial vein cross-sectional area but had no effect on the femoral and popliteal deep veins. Interestingly, some studies also reported that, irrespective of the effects on the luminal diameter, MCS lead to an increase in the blood flow in deep veins ${ }^{9}$. It can be hypothesised, from all these results, that MCS, by increasing the tissue pressure, are responsible for emptying the blood present in the micro-circulation. This blood is forced into the main deep veins which carries the blood back to the heart. Lower leg deep veins therefore carry more blood during compression (increased venous blood flow) but do not see their luminal diameter decreased, as observed clinically. The fact that the deep veins are not significantly narrowed by MCS is actually sound because, otherwise, the blood return would have been hindered by MCS. It is envisaged to investigate in the near future the response of the deep micro-circulation to external compression. As reported in a recent study by Grenier et al. ${ }^{12}$, work on the effect of compression on the micro-circulation is already under progress. Using skin thermal conductivity sensors, the authors demonstrated that a moderate interface pressure applied by compression stockings had a direct positive effect on the skin micro-circulatory activity.

The current biomechanical model is currently capable of simulating the response of lower leg intramuscular and inter-compartment deep veins to both elastic compression and muscle activation in 2D under the assumption of plane strain. The next step will be to extend this model to include 3D effects in view of developing patient-specific tools. Another future perspective is to study the effect of elastic compression and muscle activation on blood circulation. More 
specifically, one aspect which has never been addressed in the literature is the response of perforator veins - which connect the superficial veins to the deep veins - and which play an important role in the apparition and development of venous insufficiency.

\section{Conclusion}

We have elaborated a 2D FE biomechanical model of the lower leg to study the response of the main deep veins to both elastic compression and muscle contraction. The integration of the biomechanical action of muscle activation in the model provided a useful basis for improving our current understanding of the mechanism by which MCS convey their benefits. More especially, preliminary results showed that it is mainly muscle activation that is responsible for narrowing deep veins luminal diameter, not the interface pressure applied by commercially available MCS which is insufficient to have a significant impact. These results are in good agreement with many clinical studies that support the idea that the benefits of action of MCS on lower leg deep veins are not correlated to a decrease in the vein luminal cross-sectional area. The developed approach opens the way to further work, such as, for example, the development of biomechanical models to study perforator veins - which connect the superficial veins to the deep veins - and which play an important role in the apparition and the development of venous insufficiency.

\section{Acknowledgements}

None.

\section{References}

1. AFNOR. NF G30-102. Article de bonneterie - Détermination de la pression de contention. AFNOR, 1986. 
2. Agu, O., G. Hamilton, and D. Baker. Graduated compression stockings in the prevention of venous thromboembolism. British Journal of Surgery 86:992-1004, 1999.

3. Albin, T. J. In Vivo Estimation of the Coefficient of Friction between Extrinsic Flexor Tendons and Surrounding Structures in the Carpal Tunnel. Proceedings of the Human Factors and Ergonomics Society Annual Meeting 31:323-324, 1987.

4. Bassez, S., P. Flaud, and M. Chauveau. Modeling of the Deformation of Flexible Tubes Using a Single Law: Application to Veins of the Lower Limb in Man. J Biomech Eng 123:58-65, 2000.

5. Blemker, S. S., P. M. Pinsky, and S. L. Delp. A 3D model of muscle reveals the causes of nonuniform strains in the biceps brachii. Journal of Biomechanics 38:657-665, 2005.

6. Bouman, A. C., and A. ten Cate-Hoek. Timing and duration of compression therapy after deep vein thrombosis. Phlebology 29:78-82, 2014.

7. Dai, G., J. P. Gertler, and R. D. Kamm. The Effects of External Compression on Venous Blood Flow and Tissue Deformation in the Lower Leg. Journal of Biomechanical Engineering 121:557, 1999.

8. Dolibog, P., A. Franek, J. Taradaj, P. Dolibog, E. Blaszczak, A. Polak, L. Brzezinska-Wcislo, A. Hrycek, T. Urbanek, J. Ziaja, and M. Kolanko. A comparative clinical study on five types of compression therapy in patients with venous leg ulcers. International Journal of Medical Sciences 11:34-43, 2014.

9. Downie, S. P., S. M. Raynor, D. N. Firmin, N. B. Wood, S. A. Thom, A. D. Hughes, K. H. Parker, J. H. N. Wolfe, and X. Y. Xu. Effects of Elastic Compression Stockings on Wall Shear Stress in Deep and Superficial Veins of the Calf. American Journal of Physiology - Heart and Circulatory Physiology 294:H2112-H2120, 2008.

10. Eberhardt, R. T., and J. D. Raffetto. Chronic Venous Insufficiency. Circulation 111:2398-2409, 2005.

11. Gloviczki, P., A. J. Comerota, M. C. Dalsing, B. G. Eklof, D. L. Gillespie, M. L. Gloviczki, J. M. Lohr, R. B. McLafferty, M. H. Meissner, M. H. Murad, F. T. Padberg, P. J. Pappas, M. A. Passman, J. D. Raffetto, M. A. Vasquez, and T. W. Wakefield. The care of patients with varicose veins and associated chronic venous diseases: Clinical practice guidelines of the Society for Vascular Surgery and the American Venous Forum. Journal of Vascular Surgery 53:2S-48S, 2011.

12. Grenier, E., C. Gehin, B. Lun, and E. McAdams. Local effect of compression stockings on skin microcirculatory activity through the measurement of skin effective thermal conductivity. , 2013. 
13. Han, H.-C. A biomechanical model of artery buckling. Journal of Biomechanics 40:3672-3678, 2007.

14. Ibegbuna, V., K. T. Delis, A. N. Nicolaides, and O. Aina. Effect of elastic compression stockings on venous hemodynamics during walking. Journal of Vascular Surgery 37:420-425, 2003.

15. Jenkyn, T. R., B. Koopman, P. Huijing, R. L. Lieber, and K. R. Kaufman. Finite element model of intramuscular pressure during isometric contraction of skeletal muscle. Physics in Medicine and Biology 47:4043, 2002.

16. Kamm, R. D. Bioengineering studies of periodic external compression as prophylaxis against deep vein thrombosis-part I: numerical studies. Journal of biomechanical engineering 104:87-95, 1982.

17. Kamm, R. D., and A. H. Shapiro. Unsteady Flow in a Collapsible Tube Subjected to External Pressure or Body Forces. Journal of Fluid Mechanics 95:1-78, 1979.

18. Kozlovsky, P., U. Zaretsky, A. J. Jaffa, and D. Elad. General tube law for collapsible thin and thick-wall tubes. Journal of Biomechanics 47:2378-2384, 2014.

19. Lattimer, C., E. Kalodiki, M. Kafeza, M. Azzam, and G. Geroulakos. Quantifying the Degree Graduated Elastic Compression Stockings Enhance Venous Emptying. European Journal of Vascular and Endovascular Surgery .doi:10.1016/j.ejvs.2013.10.020

20. Lord, R. S. A., and D. Hamilton. Graduated compression stockings (20-30 mmHG) do not compress leg veins in the standing position. ANZ Journal of Surgery 74:581-585, 2004.

21. Martinez, R., C. Fierro, P. Shireman, and H.-C. Han. Mechanical Buckling of Veins Under Internal Pressure. Annals of Biomedical Engineering 38:1345-1353, 2010.

22. Martinez, R., and H.-C. Han. The effect of collagenase on the critical buckling pressure of arteries. Molecular and cellular biomechanics 9:55-75, 2012.

23. Mayberry, J. C., G. L. Moneta, R. D. De Frang, and J. M. Porter. The influence of elastic compression stockings on deep venous hemodynamics. Journal of Vascular Surgery 13:91-100, 1991.

24. Mosti, G., and H. Partsch. Improvement of Venous Pumping Function by Double Progressive Compression Stockings: Higher Pressure Over the Calf is More Important Than a Graduated Pressure Profile. European Journal of Vascular and Endovascular Surgery 47:545-549, 2014.

25. Narracott, A. J., G. W. John, R. J. Morris, J. P. Woodcock, D. R. Hose, and P. V. Lawford. A Validated Model of Calf Compression and Deep Vessel Collapse During External Cuff Inflation. IEEE Transactions on Biomedical Engineering 56:273 -280, 2009. 
26. Nazari, M. A., P. Perrier, and Y. Payan. The Distributed Lambda ( $\lambda$ ) Model (DLM): A 3-D, Finite-Element Muscle Model Based on Feldman's $\lambda$ Model; Assessment of Orofacial Gestures. Journal of speech, language, and hearing research 56:S1909-1923, 2013.

27. Nicolaides, A. N., V. V. Kakkar, E. S. Field, and J. T. G. Renney. The origin of deep vein thrombosis: a venographic study. British Journal of Radiology 44:653-663, 1971.

28. Orsted, H. L., L. Radke, and R. Gorst. The impact of musculoskeletal changes on the dynamics of the calf muscle pump. Ostomy Wound Manage 47:18-24, 2001.

29. Partsch, B., and H. Partsch. Calf compression pressure required to achieve venous closure from supine to standing positions. Journal of Vascular Surgery 42:734-738, 2005.

30. Partsch, H., G. Mosti, and F. Mosti. Narrowing of leg veins under compression demonstrated by magnetic resonance imaging (MRI). International Angiology: A Journal of the International Union of Angiology 29:408$410,2010$.

31. Rohan, C. P.-Y., P. Badel, B. Lun, D. Rastel, and S. Avril. Biomechanical response of varicose veins to elastic compression: A numerical study. Journal of Biomechanics 46:599-603, 2013.

32. Stecco, C., V. Macchi, A. Porzionato, F. Duparc, and R. De Caro. The fascia: the forgotten structure. Italian Journal of Anatomy and Embryology 116:127-138, 2011.

33. Van der Velden, S., and H. Neumann. The post-thrombotic syndrome and compression therapy. Phlebology 29:83-89, 2014.

34. Wang, Y., S. Downie, N. Wood, D. Firmin, and X. Y. Xu. Finite element analysis of the deformation of deep veins in the lower limb under external compression. Medical Engineering \& Physics 35:515-523, 2013. 


\section{List of tables}

\begin{tabular}{|l|l|}
\hline Table 1 & Material constitutive laws and parameters. \\
\hline Table 2 & Contact and constraint parameters. \\
\hline
\end{tabular}

\section{List of figures}

\begin{tabular}{|c|c|}
\hline Figure 1 & $\begin{array}{l}\text { Geometric model of (a) the calf with an intra-muscular vein (soleus vein) } \\
\text { and (b) the calf with inter-compartment veins (posterior tibial and fibular } \\
\text { veins and arteries). The arrows are a representation of the biomechanical } \\
\text { action of muscle activation on the intra-muscular vein wall (modelled in } \\
\text { this study as pressure boundary conditions imposed on the internal faces of } \\
\text { the soleus muscle of the SPC and the DPC muscles). The MR image slice } \\
\text { was chosen in such a way that it corresponded to the saphenian junction. } \\
\text { This anatomical landmark is clinically relevant for vascular surgeons and is } \\
\text { easily identifiable on the MR images. }\end{array}$ \\
\hline Figure 2 & $\begin{array}{l}\text { Summary of the proposed approach to study the biomechanical response of } \\
\text { intramuscular deep vein to the combined action of elastic compression and } \\
\text { muscular contraction. (a) Initial MR image of the calf (b) Image } \\
\text { segmentation in Matlab (c) Step 1: Response to blood pressure loading and } \\
\text { initial stress in vein wall (d) Step 2: Biomechanical response to elastic } \\
\text { compression (colour map represents increase in hydrostatic pressure) (e) } \\
\text { Step 3: Biomechanical response to both elastic compression and muscular }\end{array}$ \\
\hline
\end{tabular}




\begin{tabular}{|c|c|}
\hline & contraction. \\
\hline Figure 3 & $\begin{array}{l}\text { Summary of the proposed approach to study the biomechanical response of } \\
\text { inter-compartment deep veins to the combined action of elastic } \\
\text { compression and muscular contraction. The model consists of the posterior } \\
\text { tibial artery and veins and the peroneal artery and veins. (a) Initial MR } \\
\text { image of the calf (b) Image segmentation in Matlab (c) Step 1: Simulating } \\
\text { non-zero initial stress state to approximate the non-zero in vivo state of the } \\
\text { leg. Muscle compartments are pushed aside, contact conditions are defined } \\
\text { with veins and the equilibrium is calculated (d) Initial state of the } \\
\text { biomechanical model (e) Step 2: Biomechanical response to elastic } \\
\text { compression (colour map represents increase in hydrostatic pressure) (e) } \\
\text { Step 3: Biomechanical response to both elastic compression and muscular } \\
\text { contraction. }\end{array}$ \\
\hline Figure 4 & $\begin{array}{l}\text { Muscle activation of simplified } 3 \mathrm{D} \text { muscle is modelled. Three vein } \\
\text { positions are considered: (a) the vein is centered on the axis of the muscle } \\
\text { (b) the vein is positioned at } 30 \% \text { of the radius of the muscle (c) the vein is } \\
\text { positioned at } 50 \% \text { of the radius of the muscle. }\end{array}$ \\
\hline Figure 5 & $\begin{array}{l}\text { Hydrostatic pressure in the soft tissues of the leg during elastic } \\
\text { compression (a) in the intramuscular model (b) in the inter-compartment } \\
\text { model in the supine position (deformed configuration). }\end{array}$ \\
\hline Figure 6 & $\begin{array}{l}\text { Biomechanical response of the intra-muscular deep vein to the combined } \\
\text { mechanical action of external compression and muscle activation for both }\end{array}$ \\
\hline
\end{tabular}




\begin{tabular}{|l|l|}
\hline Figure 7 & $\begin{array}{l}\text { the supine and standing positions. } \\
\text { to the combined mechanical action of external compression and muscle } \\
\text { activation in the supine position. The average response of veins is } \\
\text { represented with a dashed line. }\end{array}$ \\
\hline Figure 8 & $\begin{array}{l}\text { Sensibility of the model to the different parameters investigated. The } \\
\text { relative influence of each parameter set is represented as a function of the } \\
\text { relative influence on (a) the variation of the cross section of the vein (red } \\
\text { bars) and (b) the muscle activation (pressure boundary condition) required } \\
\text { to collapse the vein completely (blue bars). }\end{array}$ \\
\hline Figure 9 & \begin{tabular}{l} 
Hydrostatic stress pressure contour plot for the three vein positions. \\
\hline
\end{tabular} \\
\hline
\end{tabular}




\begin{tabular}{|c|c|c|c|}
\hline Material & MODEL & Material parameters & Source \\
\hline Fat & $\begin{array}{l}\text { Hyper-elastic Neo- } \\
\text { Hookean }\end{array}$ & $\begin{array}{l}\mathrm{C}_{10}=0.005 \mathrm{MPa} \\
\mathrm{D}_{1}=0.14 \mathrm{MPa}^{-1}\end{array}$ & 8 \\
\hline Muscle & $\begin{array}{l}\text { Hyper-elastic Neo- } \\
\text { Hookean }\end{array}$ & $\begin{array}{l}\mathrm{C}_{10}=0.003 \mathrm{MPa} \\
\mathrm{D}_{1}=0.14 \mathrm{MPa}^{-1}\end{array}$ & \\
\hline Skin & $\begin{array}{l}\text { Hyper-elastic Neo- } \\
\text { Hookean }\end{array}$ & $\begin{array}{l}\mathrm{C}_{10}=0.1 \mathrm{MPa} \\
\mathrm{D}_{1}=0.14 \mathrm{MPa}^{-1}\end{array}$ & \\
\hline $\begin{array}{l}\text { Muscular } \\
\text { aponeurosis }\end{array}$ & $\begin{array}{l}\text { Hyper-elastic Neo- } \\
\text { Hookean }\end{array}$ & $\begin{array}{l}\mathrm{C}_{10}=10 \mathrm{MPa} \\
\mathrm{D}_{1}=0.14 \mathrm{MPa}^{-1}\end{array}$ & \\
\hline MCS & Linear elastic & $\begin{array}{l}\mathrm{E}=0.39 \mathrm{MPa} \\
v=0.49\end{array}$ & $24^{-}$ \\
\hline $\begin{array}{l}\text { Vein wall } \\
\text { (supine) }\end{array}$ & $\begin{array}{l}\text { Hyper-elastic Neo- } \\
\text { Hookean }\end{array}$ & $\begin{array}{l}\mathrm{C}_{10}=0.016 \mathrm{MPa} \\
\mathrm{D}_{1}=62 \mathrm{MPa}^{-1}\end{array}$ & $24^{-}$ \\
\hline $\begin{array}{l}\text { Vein wall } \\
\text { (standing) }\end{array}$ & $\begin{array}{l}\text { Hyper-elastic Neo- } \\
\text { Hookean }\end{array}$ & $\begin{array}{l}\mathrm{C}_{10}=0.14 \mathrm{MPa} \\
\mathrm{D}_{1}=7 \mathrm{MPa}^{-1}\end{array}$ & $-24^{-}$ \\
\hline Artery wall & $\begin{array}{l}\text { Hyper-elastic Neo- } \\
\text { Hookean }\end{array}$ & $\begin{array}{l}\mathrm{C}_{10}=0.017 \mathrm{MPa} \\
\mathrm{D}_{1}=0.14 \mathrm{MPa}^{-1}\end{array}$ & $-28^{--}$ \\
\hline
\end{tabular}




\begin{tabular}{|c|c|}
\hline Interface & CONTACT/CONSTRAINT PROPERTIES \\
\hline Skin-MCS & $\begin{array}{l}\text { Tangential Behaviour: } \\
\text { Friction formulation=PENALTY } \\
\text { Friction coefficient }=0.3^{10} \\
\text { Normal Behaviour: } \\
\text { Pressure-overclosure relationship=HARD } \\
\text { Enforcement method=PENALTY }\end{array}$ \\
\hline Fat-aponeurosis, & Tangential Behaviour: \\
\hline Muscle-aponeurosis Muscle- & Friction formulation=PENALTY \\
\hline muscle & Friction coefficient $=0.1$ \\
\hline Muscle-vein & Normal Behaviour : \\
\hline Vein-vein & Pressure-overclosure relationship=HARD \\
\hline Vein-artery & Enforcement method=PENALTY \\
\hline Tibia-muscle & Tangential Behaviour: \\
\hline Fibula-muscle & $\begin{array}{l}\text { Friction formulation=FRICTIONLESS } \\
\text { Normal Behaviour : } \\
\text { Pressure-overclosure relationship=HARD } \\
\text { Enforcement method=PENALTY }\end{array}$ \\
\hline $\begin{array}{l}\text { Internal surfaces of veins and } \\
\text { arteries }\end{array}$ & Auto-contact \\
\hline Tibia-aponeurosis & Kinematic Tie constraint (each node on the slave surface is \\
\hline Tibia-muscle & $\begin{array}{l}\text { constrained to have the same motion as the point on the master } \\
\text { surface to which it is closest) }\end{array}$ \\
\hline
\end{tabular}




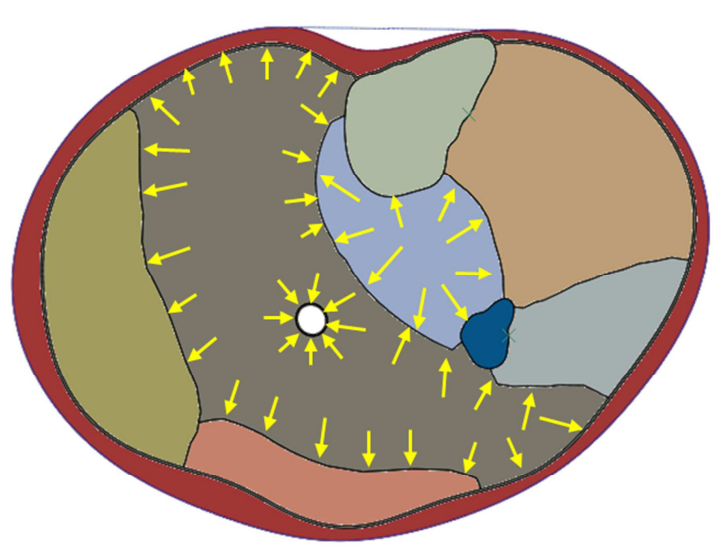

(a) Intra-muscular vein model

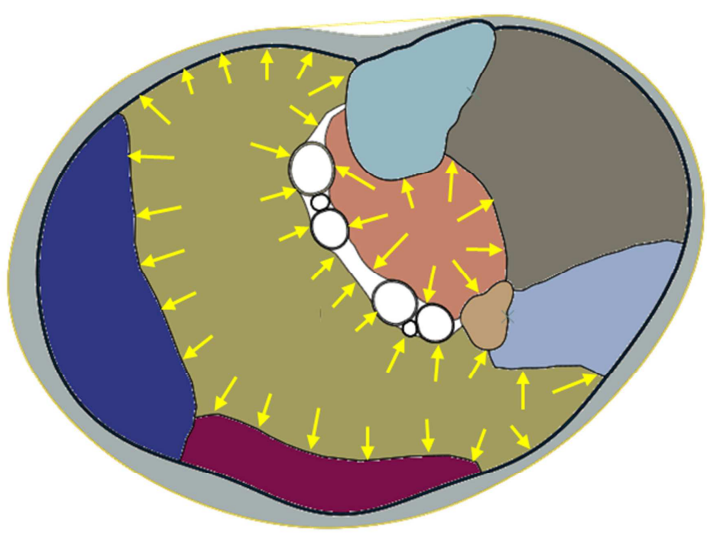

(b) Inter-compartment veins model

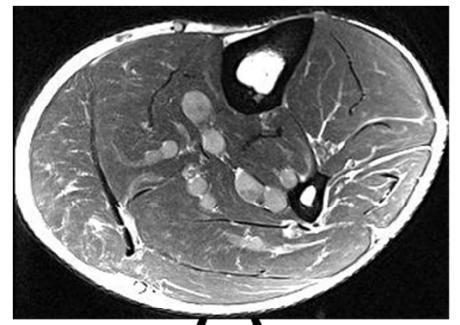

(a)

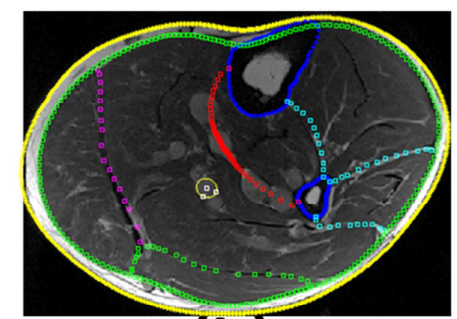

(b)

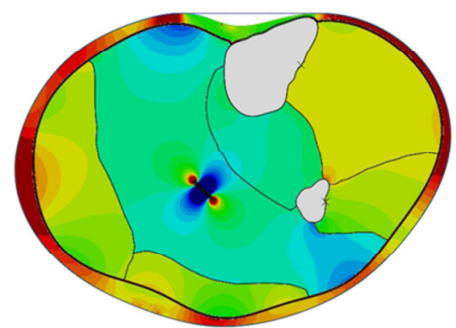

(e) Step 3

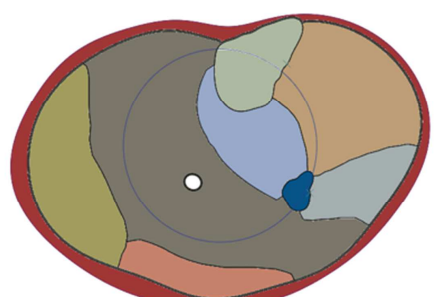

(c) Step 1

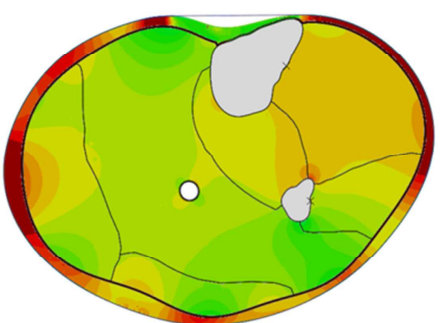

(d) Step 2 


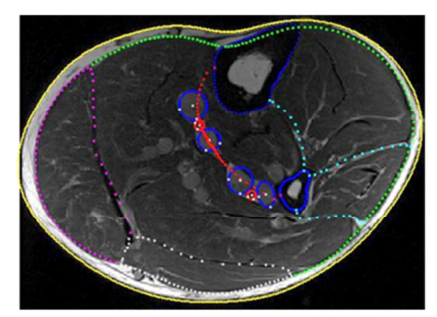

(a)

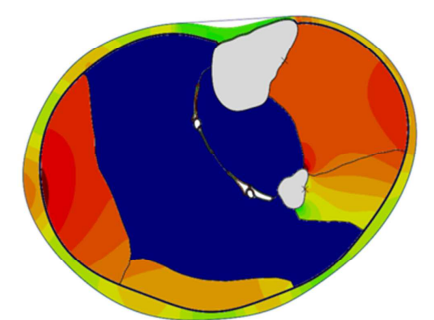

(f) Step 4

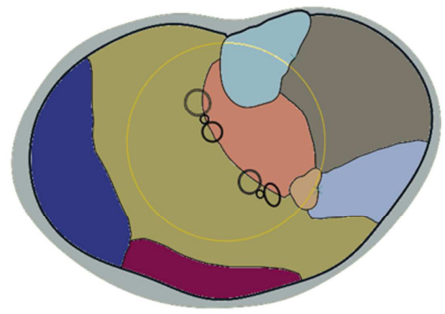

(b)

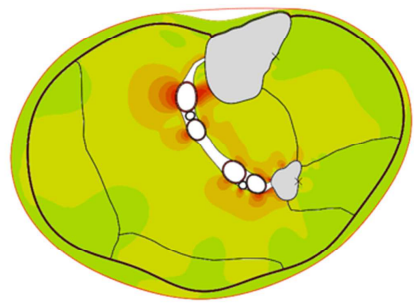

(e) Step 3

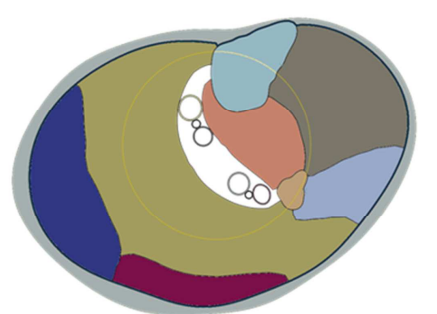

(c) Step 1

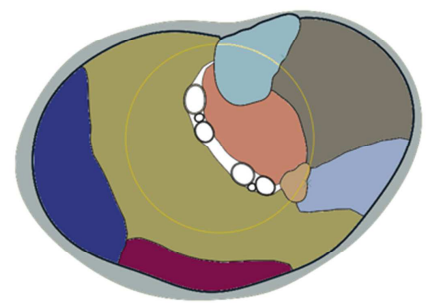

(d) Step 2

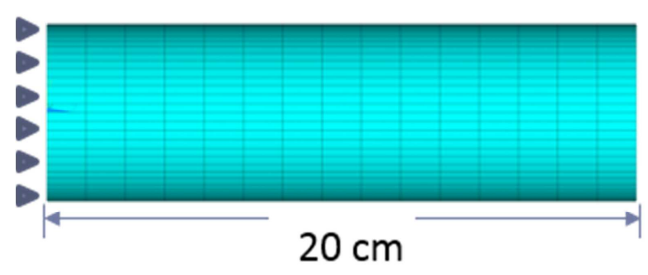

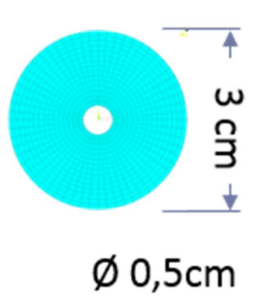

(a)

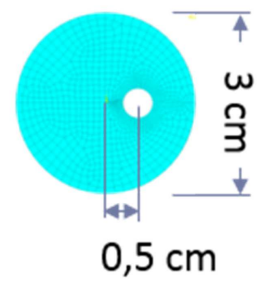

(b)

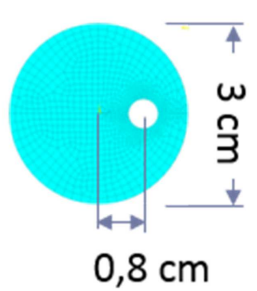

(c) 


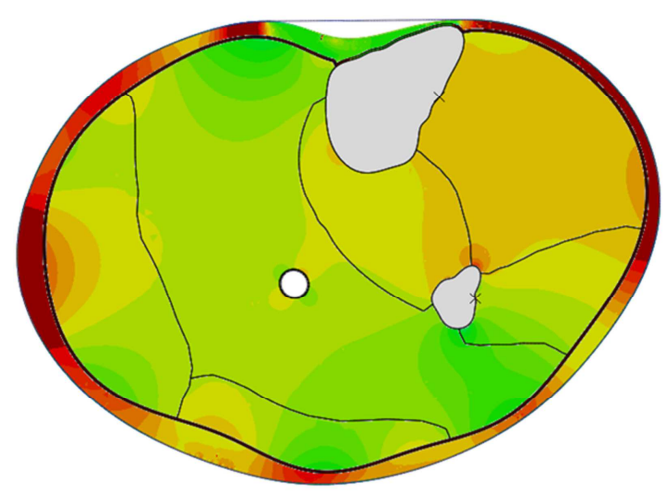

(a)

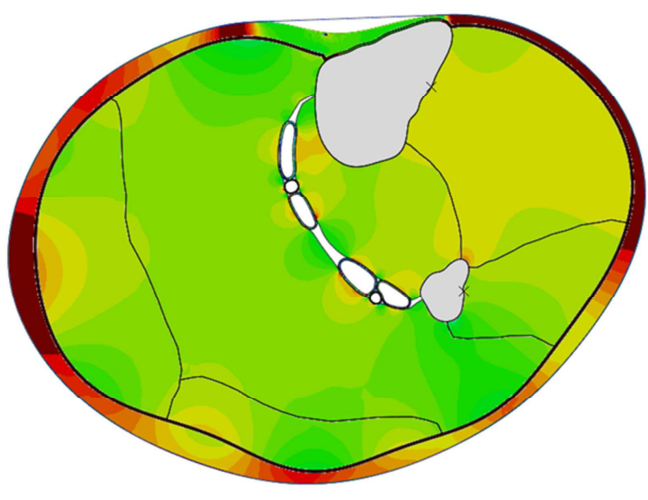

(b)

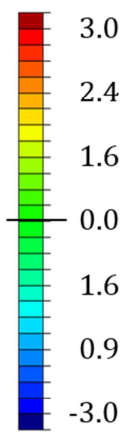

Units: kPa

Biomechanical response to the combined action of external compression (grade II) and muscle activation

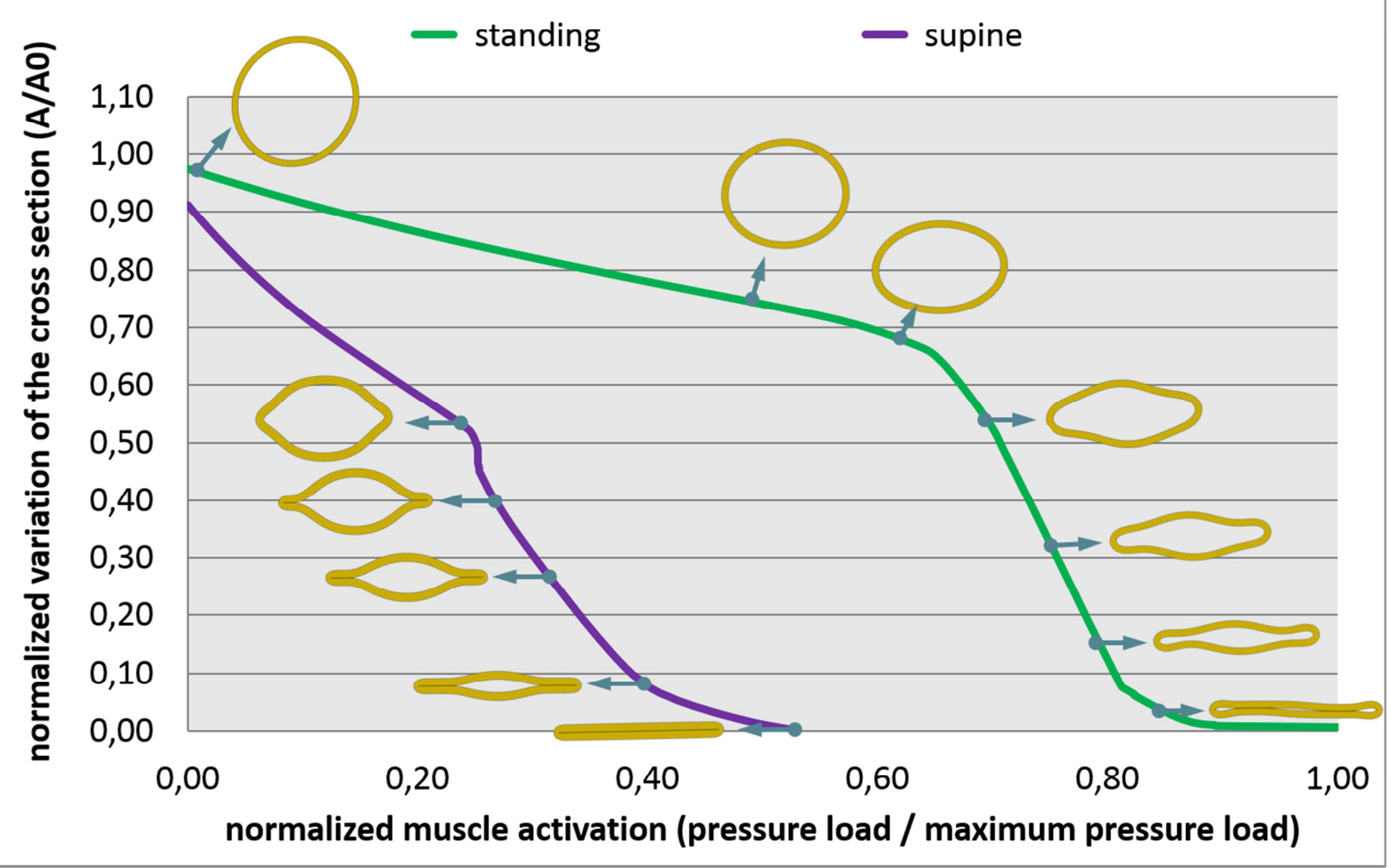




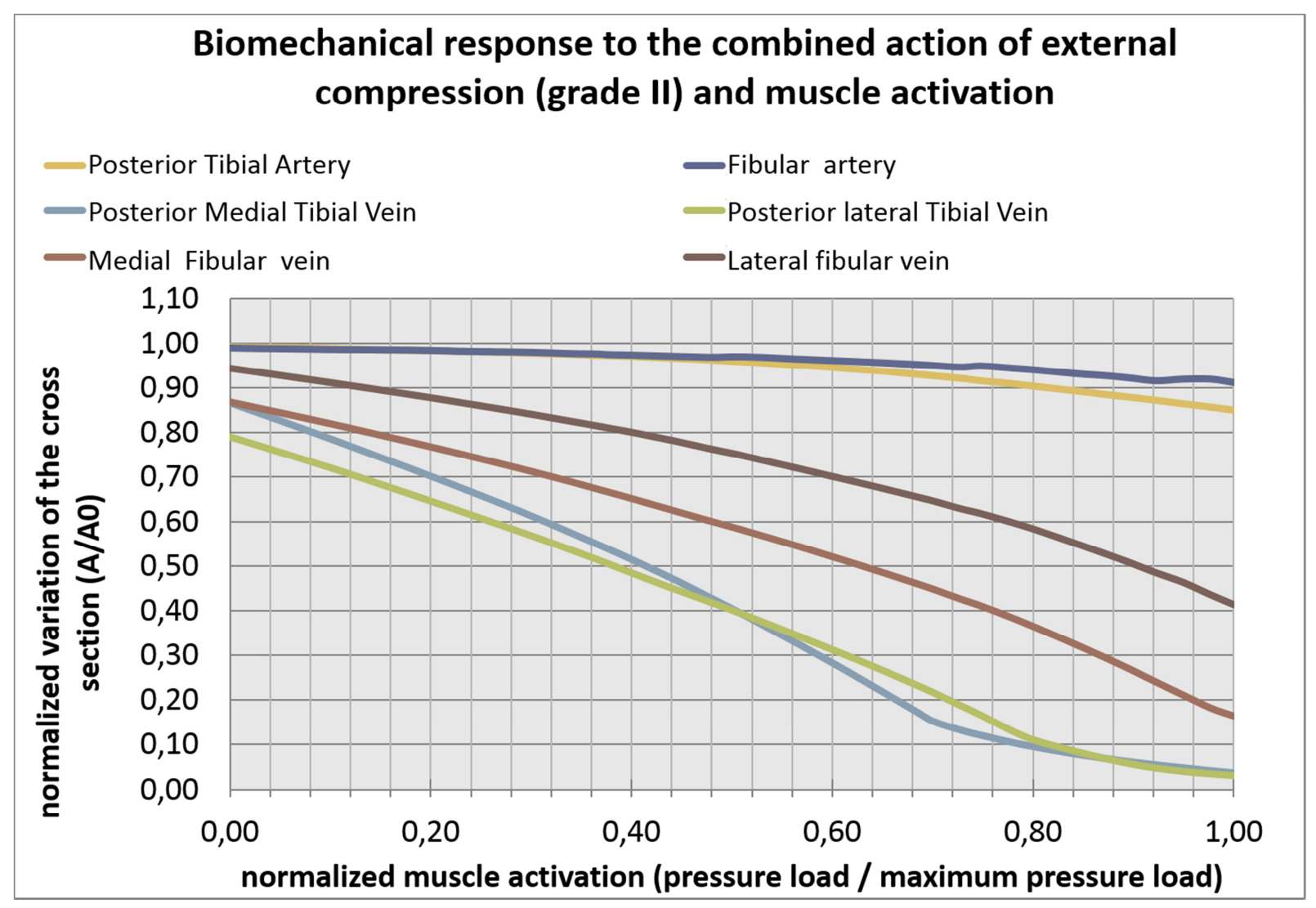


Reduction in vein cross-sectional area at the end of the compression step

Muscle contraction needed to collapse vein

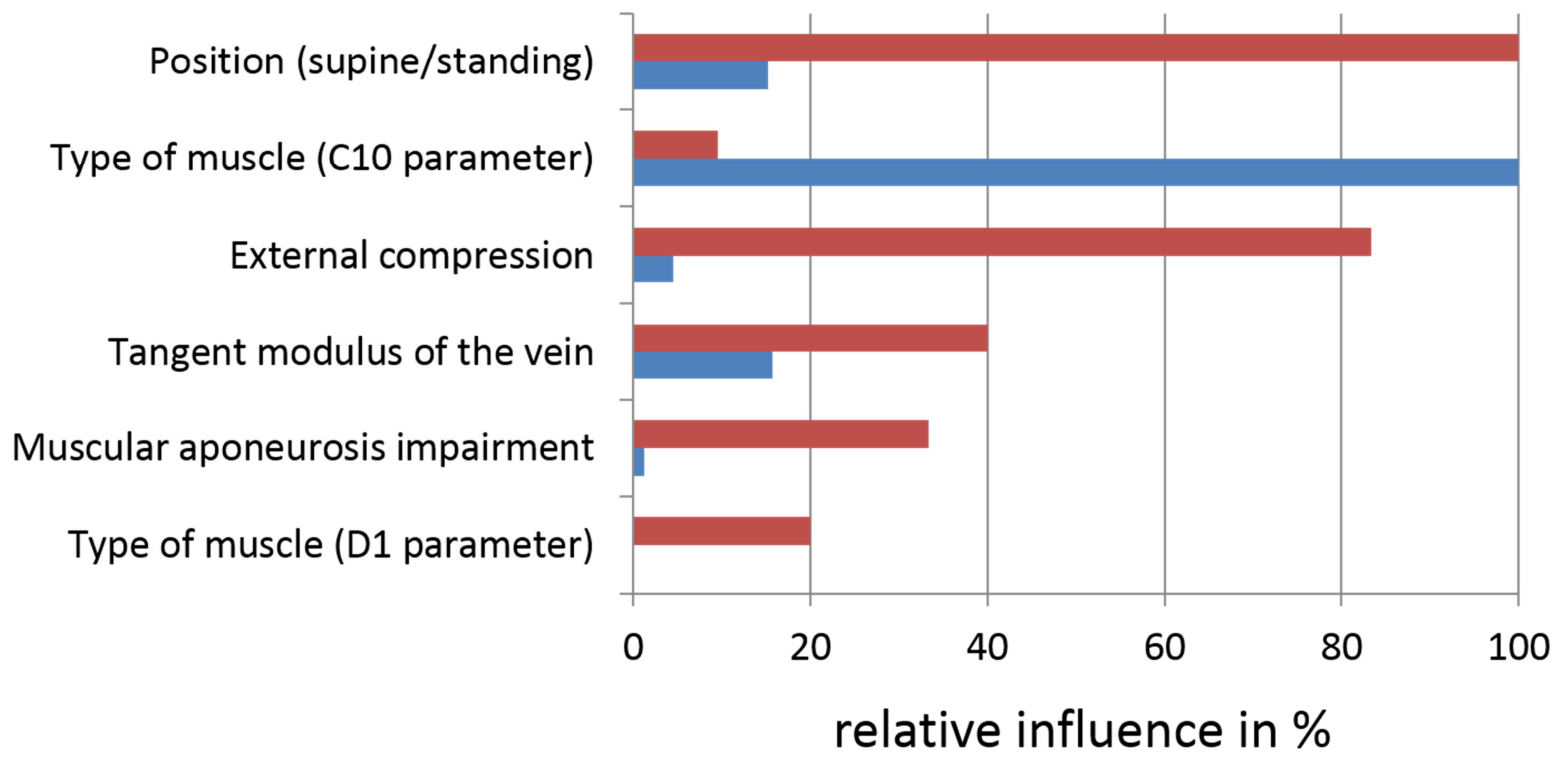

Hydrostatic pressure plot

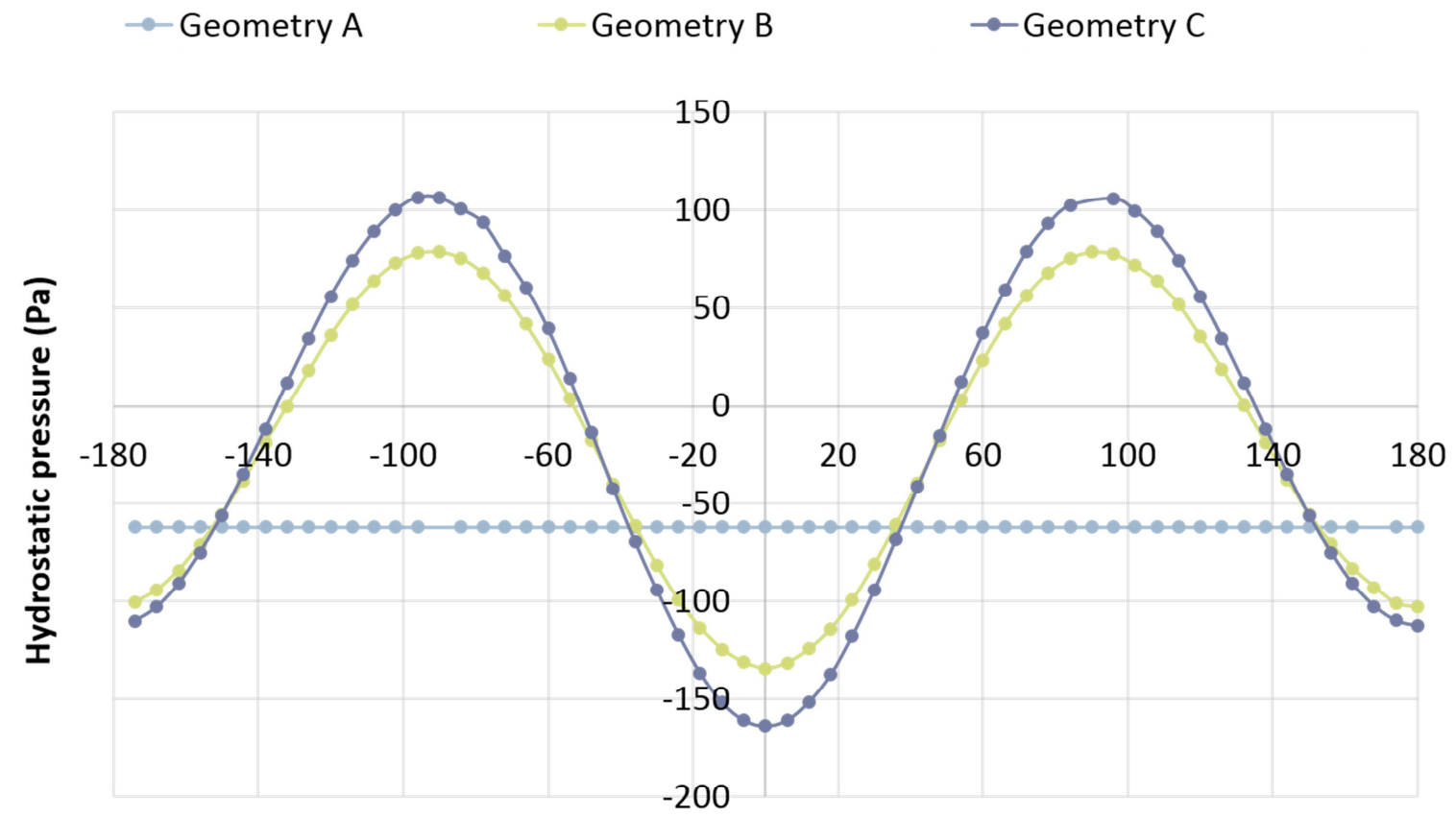

Angular position $\left({ }^{\circ}\right)$ 